\title{
Glucose-6-Phosphate Dehydrogenase Deficiency among Neonate with Jaundice in Baquba city Hadeel Ahmed Jasim $(\mathrm{BSc})^{1}$, Nadhim Ghazal Noaman $(\mathrm{PhD})^{2}$ and Shefaa Mansour Hemza $(\mathrm{PhD})^{3}$
}

\begin{abstract}
Background:Glucose -6-phosphate dehydrogenase (G6PD) deficiency is the commonest genetic disorder and is one of the most frequent red cell enzymopathies worldwide, Individuals with this disorder are prone to jaundice and hemolysis upon exposure to certain triggers, including fava bean consumption \& certain drugs

Objective:To determine the rate of G6PD deficiency among neonate with jaundice and in relation to certain epidemiological character in Baquba city.

Patients and Methods: This cross sectional study includes (155) neonates from both sex, males (106) and females (49) From 1st February to 30th July 2018, in neonatal care unit in Albatool Teaching Hospital in Baquba city, the diagnosis was done by ELISA test to detect G6PD deficiency among neonate with jaundice.

Results: Out of 155 neonates, showed male neonates \& female neonate, 39 (97.5\%), 1 (2.5\%) respectively were found to have G6PD deficiency, the mean age among G6PD deficient and normal 3.0 $\pm 1.6 ; 4.3 \pm 2.4$ days respectively, with significant difference (P 0.001), the mean TSB level among G6PD deficient neonate, normal neonates were 17.4 $\pm 3.55,15.9 \pm 3.19(\mathrm{mg} / 100 \mathrm{ml})$ respectively with significant difference $(\mathrm{P} 0.014)$.

Conclusion: The rate of G6PD deficiency was (25.8\%) among the studied neonates, It was discovered more among first, second and third age of life and it was more among male than female.

Keywords: G6PD deficiency, Enzyme deficiency, Hemolysis, Neonate jaundice.

Corresponding Author: drnadhimg@yahoo.com

Received: $4^{\text {th }}$ November 2018

Accepted: $27^{\text {th }}$ November 2018

https://doi.org/10.26505/DJM

${ }^{1,2}$ Family \& Community Medicine - College of Medicine - University of Diyala - Diyala - Iraq.

${ }^{3}$ Albatool Teaching Hospital- Diyala - Iraq.

\section{Introduction}

Glucose-6-phosphate dehydrogenase (G6PD) deficiency is an $\mathrm{x}$-linked disorder, commonly found in peoples of Mediterranean or African descent, G6PD deficiency is the most prevalent enzyme deficiency [1].The association between neonatal jaundice and the red cell G6PD deficiency has been well reported among

certain ethnic groups, such as Greeks, Chinese and Italians [2].

Peoples with this hereditary disease are more susceptible to develop jaundice and hemolysis due to exposure to many triggers, such as consumption of fava bean, this is what is called "favism." The importance of G6PD enzyme in the initiation of NADPH
\end{abstract}


will maintain the reducing state of the glutathione to serve as an antioxidant[3]. The most polymorphic loci for G6PD gene is $\mathrm{X}$ chromosome [4].

Individuals with this disorder will have a wide range of clinical and biochemical phenotypes due to multiple levels of enzyme activity and protein variants [5]. The major risk factor that explain the heterozygous female newborns with G6PD deficiency is with high frequency of sever neonatal hyperbilirubinemia including, decreased bilirubin conjugation, with promoter polymorphism for the gene for the bilirubinconjugating enzyme, uridine 50-diphosphoglucuronoslytransferase 1A1 [6].

Favism is a life-threatening form of acute hemolytic anemia (AHA) especially in children [7]. (G6PD) deficiency is a necessary but not a sufficient cause of favism. Presumably some other factors, probably also genetic and very likely related to metabolism of the active ingredients in the beans is involved [8]. Patients with favism are always G6PD deficient, but not all G6PD deficient individuals develop haemolysis when they ingest fava beans[9]. The clinical presentation of G6PD deficiency is various, due to the broad distribution of variants across the protein and the potential for multidimensional biochemical effects[10].

After exposure, sudden increase in body temperature, yellow coloring of skin and mucous membrane, dark yellow -orange urine, jaundice, pallor, chills, general deterioration of physical condition, nausea, fatigue, heavy fast breathing and weak rapid pulse with or without abdominal and back pain, are sudden in onset[11]. Extreme neonatal hyperbilirubinemia is the most potentially devastating complication associated with G6PD deficiency and this complication may be of sudden onset on the level of TSB serum/plasma may increase rapid enough to dangerous levels[13].

Therapy for neonatal hyperbilirubinemia resulting from G6PD deficiency includes phototherapy or exchange transfusion to prevent kernicterus. Phototherapy is definitively effective for neonatal hyperbilirubinemia and the mainstay of treatment in all major national documents [14].

\section{Patients and Methods}

A cross-sectional study was conducted in Albatool teaching hospital, Baquba city, Diyala governorate, including (155) neonates from both sex, males (106) and females (49) From $1^{\text {st }}$ February to $30^{\text {th }}$ July 2018, in neonatal care unit. all neonates whom admitted with jaundice in this period was examined for G6PD deficiency using ELISA test by expert personal in the laboratory of the hospital, also test was done for TSB, Hb, $\mathrm{PCV}$, blood group and $\mathrm{Rh}$ of mother and neonate was done.

Information was taken directly from neonate's mother through direct questionnaire (interview). And from the records, including: Age in days, sex, Residence, maturity, birth weight, Onset of Jaundice, activity, feeding drug intake during last trimester, mode of therapy. 


\section{Statistical analysis}

Analysis of data was carried out using the available statistical package of SPSS-24. Data were presented in simple measures of frequency, percentage, mean, standard deviation, and range. $\mathrm{t}$ - test and $\mathrm{X} 2$ test was used.

Statistical significance was considered whenever the $\mathrm{P}$ value was equal or less than 0.05 .

\section{Results}

A total of 155 neonate with jaundice, A positive cases with 1; G6PD deficiency were $40(25.8 \%)$ while the normal cases were $115(74.2 \%)$ and it shows it is mostly distributed among the neonate with age 2 days $14(35 \%)$, among neonate with age 3 days $11(27 \%)$, age 5 days $6(15 \%)$ and age 1 day $5(12 \%)$ as seen in Table (1), Table (2) showed the percentage of males were $39(97.51 \%)$ with G6PD and female 1(2.51), While the normal males were 67(58.5\%), female $48(41.71 \%)$ which is a highly significant statistically among male than female ( $\mathrm{P}$ 0.0001), According to Table (3) showed the distribution of G6PD deficiency among the preterm and full term neonate. A total number of 155 showed the preterm neonate with appositive result was $13(32.5 \%)$ while a negative result was $16(13.9 \%)$ with highly statistical significant (P 0.009), table 4 showed that it is mostly distributed among the neonate with age 2 days 14(35\%), While among neonate with age 3days 11(27\%), And those of age 5 days $6(15 \%)$ and age 1 day
$5(12 \%)$ (P 0.001), Table 5 shows, lethargic 4 (2.6\%), weak 27 (17.4\%) and good 124 (80\%), with statistical significant among good then others (P 0.014), Table (5) showed that breast feeding was $20(12.9 \%)$, bottle feeding was $84(54.2 \%)$ and mixed 51 $(32.9 \%)$, with statistical significant among bottle feeding than others (P 0.001).

There was no $\mathrm{Rh}$ negative among neonate with G6PD deficiency while the normal Rh negative was $18(157 \%)$ (P0.314), while all G6PD deficient neonates were $\mathrm{Rh}$ positive 40(100\%) and the normal neonate 97(84.3\%).P 0.008 as Table (6). Table (7) showed the mean age among G6PD deficient and normal 3.0 $\pm 1.6 ; 4.3 \pm 2.4$ days respectively, with significant difference $(P$ 0.001), Birth weight mean among G6PD deficient and normal neonates were $2.963 \pm 0.369$ and $3.100 \pm 0.415 \quad \mathrm{Kg}$ respectively with no significant difference, the mean days of onset of jaundice among G6PD deficient and normal neonates were $1.2 \pm 1.2$ and $2.1 \pm 1.6$ days respectively with significant difference ( $P$ 0.001), the mean TSB level among G6PD deficient neonate, normal neonates were $17.4 \pm 3.55,15.9 \pm 3.19$ $(\mathrm{mg} / 100 \mathrm{ml})$ respectively with significant difference (P 0.014), the mean of hemoglobin among G6PD deficient and normal neonates were $\quad 16.4 \pm 1.07$ and $16.4 \pm 1.04 \quad(\mathrm{~g} / \mathrm{dl})$ respectively, the mean of $\mathrm{PCV} \%$ among G6PD deficient and normal neonates were $55.2 \pm 7.35,57.7 \pm 9.66$ respectively. 
Table (1): Distribution of G6PD deficiency among neonate with jaundice according to their age discovered in days.

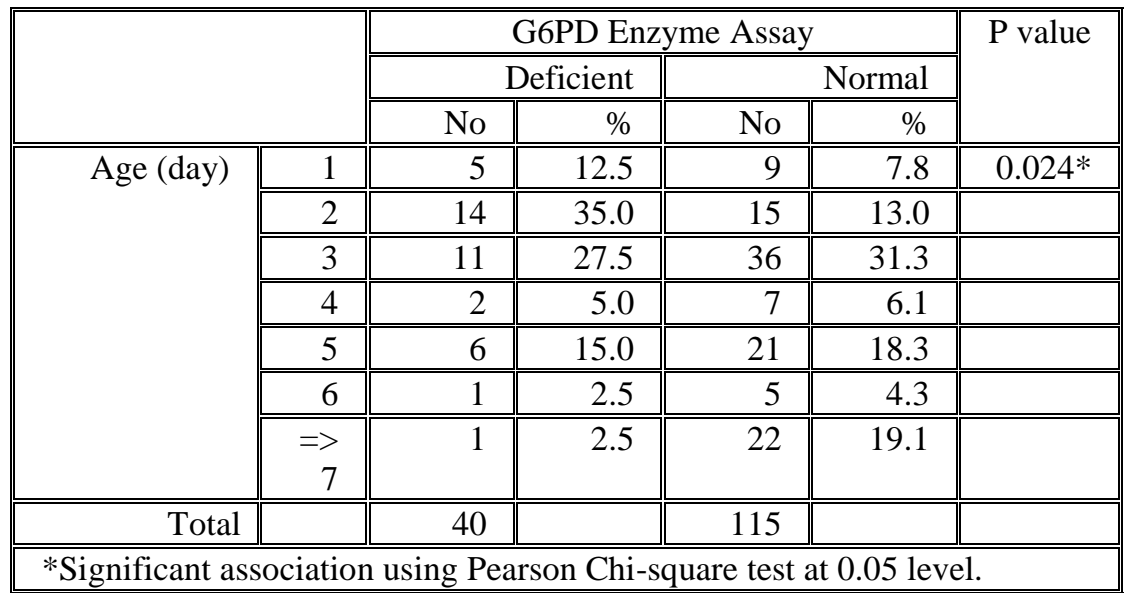

Table (2): Distribution of G6PD deficiency among neonate with jaundice according to their gender.

\begin{tabular}{|c|c|c|c|c|c|c|}
\hline & \multicolumn{4}{|c|}{ G6PD Enzyme Assay } & \multirow[t]{3}{*}{$\mathrm{P}$ value } \\
\hline & & \multicolumn{2}{|c|}{ "Deficient } & \multicolumn{2}{|c|}{ Normal } & \\
\hline & & No & $\%$ & No & $\%$ & \\
\hline \multirow[t]{2}{*}{ Sex } & Male & 39 & 97.5 & 67 & 58.3 & $0.0001 *$ \\
\hline & Female & $\overline{11}$ & 2.5 & 48 & 41.7 & \\
\hline Total & & 40 & & 115 & & \\
\hline
\end{tabular}

Table (3): Distribution of G6PD deficiency among neonate with jaundice according to their gestational age.

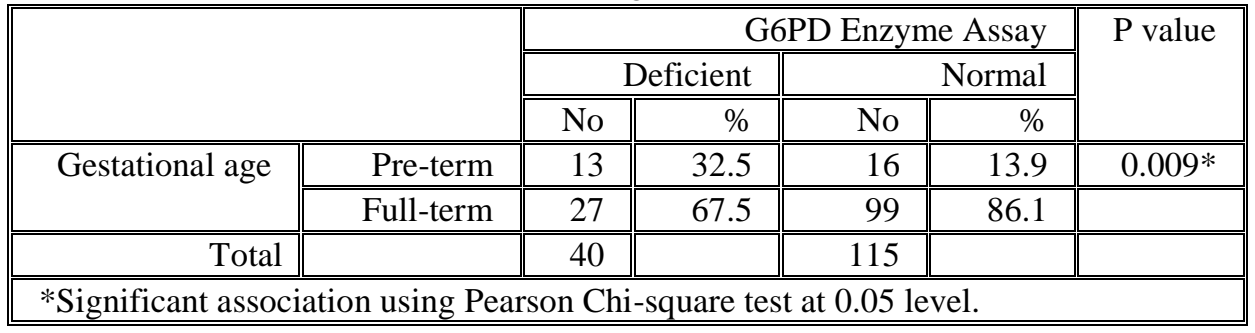


Table (4): Distribution of G6PD deficiency among neonate with jaundice according to onset of jaundice.

\begin{tabular}{|c|c|c|c|c|c|c|}
\hline & \multicolumn{4}{|c|}{ G6PD Enzyme Assay } & \multirow[t]{3}{*}{$P$ value } \\
\hline & & \multicolumn{2}{|c|}{ Deficient } & \multicolumn{2}{|c|}{ Normal } & \\
\hline & & No & $\%$ & No & $\%$ & \\
\hline \multirow[t]{5}{*}{ Onset of Jaundice } & Since birth & 8 & 20.0 & 15 & 13.0 & $0.001^{*}$ \\
\hline & Day 1 & 22 & 55.0 & 28 & 24.3 & \\
\hline & Day 2 & 8 & 20.0 & 38 & 33.0 & \\
\hline & Day 3 & 1 & 2.5 & 14 & 12.2 & \\
\hline & Day 4-7 & 1 & 2.5 & 20 & 17.4 & \\
\hline Total & & $\overline{440}$ & & 1115 & & \\
\hline
\end{tabular}

Table (5): Distribution of G6PD deficiency among neonate with jaundice according to feeding.

\begin{tabular}{|c|c|c|c|c|c|c|}
\hline & \multicolumn{4}{|c|}{ "G6PD Enzyme Assay } & \multirow{3}{*}{$\mathrm{P}$ value } \\
\hline & & \multicolumn{2}{|c|}{ Deficient } & \multicolumn{2}{|c|}{ Normal } & \\
\hline & & No & $\%$ & No & $\%$ & \\
\hline \multirow[t]{3}{*}{ Feeding } & Breast & 84 & $\overline{10.0}$ & 16 & 13.9 & $0.0001 *$ \\
\hline & Bottle & 33 & 82.5 & $\overline{51}$ & 444.3 & \\
\hline & Mixed & 3 & 7.5 & 48 & 41.7 & \\
\hline Total & & 40 & & 115 & & \\
\hline
\end{tabular}

Table (6): Distribution of G6PD deficiency among neonate with jaundice according to Blood group of baby.

\begin{tabular}{|c|c|c|c|c|c|c|}
\hline & \multicolumn{4}{|c|}{ G6PD Enzyme Assay } & \multirow[t]{3}{*}{$P$ value } \\
\hline & & \multicolumn{2}{|c|}{ Deficient } & \multicolumn{2}{|c|}{ Normal } & \\
\hline & & No & $\%$ & No & $\%$ & \\
\hline \multirow{4}{*}{$\begin{array}{l}\text { ABO Blood } \\
\text { group of Baby }\end{array}$} & A & 3 & 7.5 & 20 & $\overline{17.4}$ & 0.314 \\
\hline & $\overline{\mathrm{B}}$ & $\overline{11}$ & 2.5 & $\overline{33}$ & 2.6 & \\
\hline & $\mathrm{AB}$ & 36 & 90.0 & 92 & 80.0 & \\
\hline & $\mathrm{O}$ & - & - & - & - & \\
\hline \multirow{2}{*}{$\begin{array}{l}\text { Rh Blood group } \\
\text { of Baby }\end{array}$} & Rh-ve & - & - & $\overline{18}$ & 15.7 & $0.008 *$ \\
\hline & Rh+ve & 40 & 100 & 97 & 84.3 & \\
\hline
\end{tabular}


Table (7): Distribution of G6PD deficiency among neonate with jaundice in the studied group according to the mean, SD and range in relation to the age, birth weight, day of onset of jaundice, TSB, $\mathrm{Hb}$ and $\mathrm{PCV} \%$.

\begin{tabular}{|c|c|c|c|}
\hline & \multicolumn{2}{|c|}{ G6PD Enzyme Assay } & \multirow[t]{2}{*}{$P$ value } \\
\hline & Deficient & Normal & \\
\hline Age (day) & $3.0 \pm 1.6(10-8)$ & 4 & "0.001* \\
\hline Birth weight (Kg) & $2.963 \pm 0.369(2.0-3.5)$ & $3.100 \pm 0.415(2.0-4.0)$ & 0.065 \\
\hline $\begin{array}{l}\text { Day of onset of } \\
\text { jaundice }\end{array}$ & $1.2 \pm 1.2(0-7)$ & $2.1 \pm 1.6(0-7)$ & $0.001 *$ \\
\hline $\begin{array}{l}\text { TSB (direct) } \\
(\mathrm{mg} / 100 \mathrm{ml})\end{array}$ & $17.4 \pm 3.55(10.7-23.5)$ & 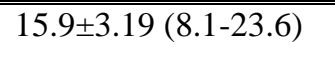 & "0.014* \\
\hline $\mathrm{Hb}(\mathrm{g} / \mathrm{dl})$ & $16.4 \pm 1.07(13.5-18.0)$ & $16.4 \pm 1.04(13.5-20.0)$ & 0.975 \\
\hline PCV (\%) & $55.2 \pm 7.35(44-70)$ & $57.7 \pm 9.66(40-77)$ & 0.123 \\
\hline
\end{tabular}

\section{Discussion}

Distribution of G6P D deficiency according to the age showed the positive result was mostly distributed among the neonate with age 2 days, age 3 days, age 5 days and age 1 day respectively as this result was agree with the study done by (Al-Naama, Al-Sadoon and Al-Naama 1987), who reports that that G6PD deficiency was mostly distributed among the neonates and this go with a study done in Basrah governorate, The study showed it was highly significant among male than female and this study is similar to study done by (Isa, et al. 2017), In Bahrain, who reported that G6PD deficiency was more in male than female. According to gestational age, the study showed that distribution of G6PD deficiency among the preterm and full term neonate, that was highly significant among full term and this was similar to study done in Nigeria, (Badejoko, et al. 2014), who reports that G6PD deficiency was highly significant among full term neonates.
Distribution of G6PD deficiency according to onset of jaundice, It showed mostly distributed among the neonate with day 1, day 2 and at time of delivery, and this agreed with the study done in Iran by (Pahlavanzadeh, et al. 2013), who showed that the jaundice began in the first week after birth, also it was similar to (Abbas 2005), in Iraq, that showed the same result. This study showed that G6PD deficiency distribution was statistically significant among active neonate than others and this agreed with (Pahlavanzadeh, et al. 2013), in Iran.

According to drug intake during last trimester, It showed no statistical difference in drug intake.

The study showed there was statistical significant among normal phototherapy, and this was similar to study done by (Eghbalian and Monsef 2007), who reported in their study that all G6PD deficient neonates and other icteric neonate were treated with normal phototherapy. 
The study showed both blood group and $\mathrm{Rh}$ of mother (statistically not significant), and this was similar to (Pahlavanzadeh, et al. 2013), in Iran, who reported in their study that there were no relationship between the relative frequency of G6PD deficiency and blood group of mother.

According to $\mathrm{ABO}$ and $\mathrm{RH}$ blood group of baby, there was no Rh negative among neonate with G6PD deficiency while all G6PD deficiency was Rh positive and this was similar to (Pahlavanzadeh, et al. 2013), who reported in their study that there was no $\mathrm{Rh}$ negative among neonate with G6PD deficiency.

\section{Conclusion}

The rate of G6PD deficiency was (25.8\%) among the studied neonates. It was found that male was affected more than female and the onset of jaundice among G6PD deficiency started at first and second day of life.

\section{Recommendations}

Screening for G6PD deficiency should be done early among neonate with jaundice and health education of the parents about the predisposing factors is needed also the doctors should be oriented about this disease.

\section{References}

[1]Nkhoma, Ella T., Charles Poole, Vani Vannappagari, Susan A. Hall, and Ernest Beutler. "The global prevalence of glucose6-phosphate dehydrogenase deficiency: A systematic review and meta-analysis" Blood Cells, Molecules, and Diseases, Vol.42, 2009: 267-278.

[2]Yaish, H. M., G. A. Niazi, M. Al-Shaalan, S. Khan, and G. S. Ahmed. "Increased incidence of hyperbilirubinaemia in 'unchallenged' glucose -6- phosphate dehydrogenase deficiency in term Saudi newborns" Annals of Tropical Pediatrics, Vol. 11, Issue 3, 1991: 259-266.

[3]Staudt , Genevieve E., and Jason Zhensheng $\mathrm{Qu}$ "Deep Hypothermic Circulatory Arrest in a Patient With Severe G6PD Deficiency." Journal of Cardiothoracic and Vascular Anesthesia, Vol. 32, Issue 3, june 2018: 1394-1397.

[4] Uyoga, Sophie, et al. "Glucose-6phosphate dehydrogenase defi ciency and the risk of malaria and other diseases in children in Kenya a case-control and a cohort study." Lancet Haematol, Vol. 2, September 23, 2015: 437-444.

[5]Cappellini, Maria Domenica, and G Fiorelli. "Glucose-6-phosphate dehydrogenase deficiency." lancet,Vol. 371, january 2008: 64-74.

[6] Riskin, Arieh Riskin, Neta Gery, Amir Kugelman, Miri Hemo, Irina Spevak, and David Bader. "Glucose-6-Phosphate Dehydrogenase Deficiency and Borderline." The Journal of Pediatrics, Vol. 161, No. 2, August 2012: 191-196.

[7]Reading, N. Scott, et al. "Favism, the commonest form of severe hemolytic anemia in Palestinian children, varies in severity with three different variants of G6PD deficiency within the same community." Blood Cells, Molecules, and Diseases, Voil.60, september 2016: 58-64.

[8] Al-Musawi, Zuhair M. , Mohammad Sh. Ali, and Ahmmed H. Matloob. "The in Vitro Effect of Chloramphenicol and Salicylate on 
Erythrocytes of Patients with Favism." The Iraqi Postgradute Medical Journal, Vol.9, No.1, 2010: 95-100.

[9] Al-Momen, Hayder H. , Muthanna F. Athab, and Anwer S. Al-Zubaidi "Glucose-6 Phosphate Dehydrogenase Deficiency in terms of hemolysis indicators and management." Journal of the Faculty of Medicine, Vol. 59, Issue 2, 2017: 122-127.

[10]Cunningham, Anna D., Alexandre Colavin, Kerwyn Casey Huang, and Daria Mochly Rosen. "Coupling between Protein Stability and Catalytic Activity Determines Pathogenicity of G6PD Variants." Cell Reports, Vol. 18, March 14, 2017: 25922599.

[11] Grace, Rachael F. , and Bertil Glader. "Red Blood Cell Enzyme Disorders." Pediatric Clinics of North America, Vol. 65, Issue 3, june 2018: 579-595.

[12] Moiz, Bushra. "A review of G6PD deficiency in Pakistani perspective." Journal of Pakistani medical association, Vol.63, No,4, April 2013: 501-503.

[13] Kaplan, Michael, Cathy Hammerman , and Vinod K. Bhutani. "The Preterm Infant: A High-Risk Situation for Neonatal Hyperbilirubinemia Due to Glucose-6Phosphate Dehydrogenase Deficiency." Clinics in Perinatology, Vol. 43, Issue 2, june 2016: 325-340.

[14] Raimondi, Francesco, Teresa Ferrara, Angela Carla Borrelli, Daniela Schettino, Claudia Parrella, and Letizia Capasso. "Neonatal hyperbilirubinemia a critical appraisal of current guidelines and evidence" Journal of Pediatric and Neonatal
Individualized Medicine (JPNIM), Vol. 1, n. 1, july 2012: 25-32. 